\title{
Modeling Erosion and Sedimentation Processes in the Chorro Creek Subwatershed to Evaluate and Develop Effective Watershed Management Approaches
}

\author{
Michael Randall and Misgana Muleta
}

\begin{abstract}
The Morro Bay Watershed, located in San Luis Obispo County, California, covers more than 48,000 acres of land and discharges into Morro Bay through the Morro Bay National Estuary (MBNE). The Chorro Creek Subwatershed consists of approximately 30,000 acres of the overall watershed. The MBNE provides an ecosystem that supports a variety of wildlife, from the common sea gull to the endangered sea otter. The estuary is also home to over 200 species of birds. The operational waterfront of the Morro Bay Harbor was and continues to be a strong supporter to the local economy of the City of Morro Bay. Numerous studies were conducted since the 1990s throughout the watershed to study the sedimentation of the estuary and bay and identified accelerated erosion and subsequent sedimentation as a major threat to sustainability of the bay. As a result, various Best Management Practices (BMPs) have been implemented in the watershed to reduce sediment loading and transport to the bay. Localized evaluations of various BMPs have been performed to investigate effectiveness of individual BMPs. This paper consolidates this information and develops a comprehensive spatially distributed watershed simulation model (1) for detailed understanding of the erosion and sedimentation processes in the watershed; (2) to evaluate a watershed scale effectiveness of the conservation practices that have been installed in the watershed; (3) to identify optimal BMP types and sites that may be used in the future to further reduce sedimentation of the bay at minimal cost; (4) to organize and document the various sources of data and studies that have been performed to date in the Chorro Creek subwatershed. Soil and Water Assessment Tool (SWAT) was used to develop the model and to evaluate the pre and post BMP implementation characteristics in the subwatershed. Combining the data and efforts of past BMP evaluations, land use, soil type, climate data, and streamflow data, statistical evaluations, and model sensitivity analysis will help build and calibrate a robust SWAT model that can be used to track BMP evaluation efforts, as well as other watershed management tasks. Through the evaluation of BMPs in the watershed, efforts can be made to implement the more successful BMPs in the watershed or in other similar watersheds. Sensitivity analysis was performed using a global sensitivity analysis method and streamflow and sediment yield was calibrated using the Shuffled Complex Evolution-University of Arizona.
\end{abstract}

\section{Introduction}

The Morro Bay Watershed (Figure 1), located in San Luis Obispo County, California, covers more than 48,000 acres of land and discharges into Morro Bay through the Morro Bay National Estuary (MBNE). The MBNE provides an ecosystem that supports a variety of plants and animals, from the common sea gull to the endangered sea otter. The estuary is also home to over 200 species of birds. The operational waterfront of the Morro Bay Harbor was and continues to be a strong supporter to the local economy of the City of Morro Bay. 


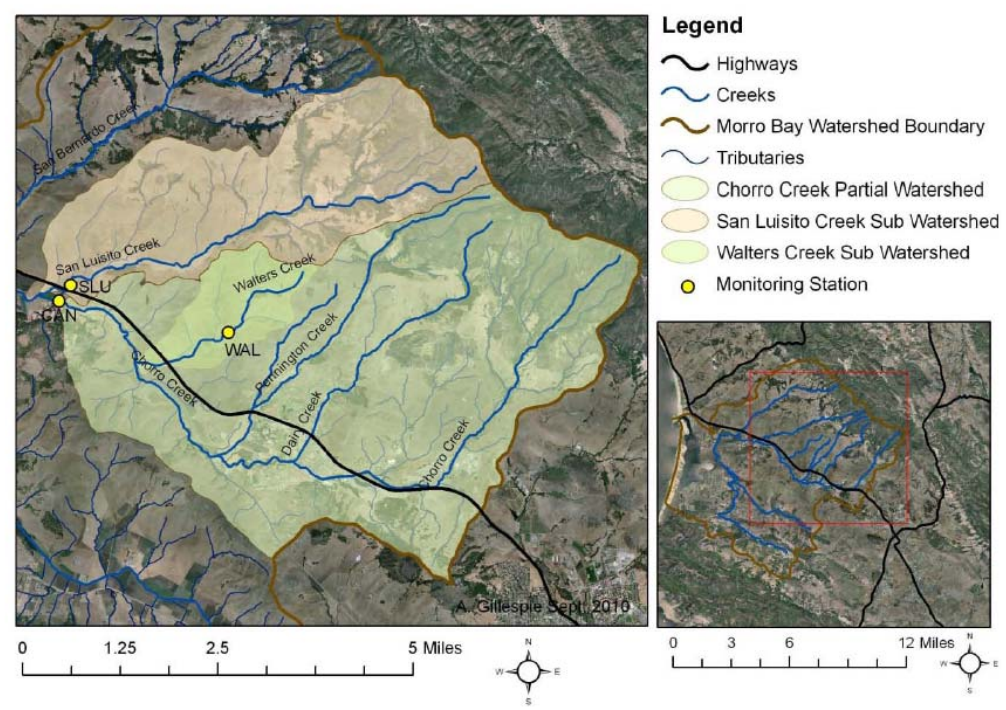

Figure 1: Chorro Watershed Study Area. (Source: MBNEP, 2010)

One of the principal contaminates of concern in this watershed is sediment due to its effects on wildlife both in the bay and in the tributary creeks. Human activity has altered the watershed over time. It is important to understand whether these activities are negatively affecting the watershed and, if so, to what extent. There are many agencies and organizations that are working to evaluate and improve sediment conditions in the watershed. Currently, sediment deposits are removed from the bay approximately every two years by the United States Army Corps of Engineers (Corps). This activity is necessary to keep the bay navigable for vessels, as well as sustain the habitat that many animals depend on. The bay is designated as a habitat area for eelgrass, which grows on the bottom of the bay. The dredging activity potentially threatens the eelgrass and animals in the bay. Depending on the effectiveness and environmental impact of sediment transport reduction best management practices (BMPs) in the tributary waterways, dredging activities in the bay could be reduced. If large amounts of sediment can be retained or captured in the tributary creeks, sediment loading to the bay would be minimized.

Numerous studies have been conducted since the 1990s throughout the watershed to study the sedimentation of the estuary and bay. These studies primarily focused on the evaluation of various BMPs to reduce sediment loading and transport through the watershed. Localized evaluations of various BMPs were performed in studies to evaluate localized effectiveness of BMPs. The Central Coast Regional Water Quality Control Board (CCRWQCB) and the California Polytechnic University (Cal Poly) conducted a best management effectiveness study, known as the paired watershed study (Figure 2), from 1992-2002 on Walters Creek and Chumash Creek in the North East portion of the Chorro Creek Watershed. 


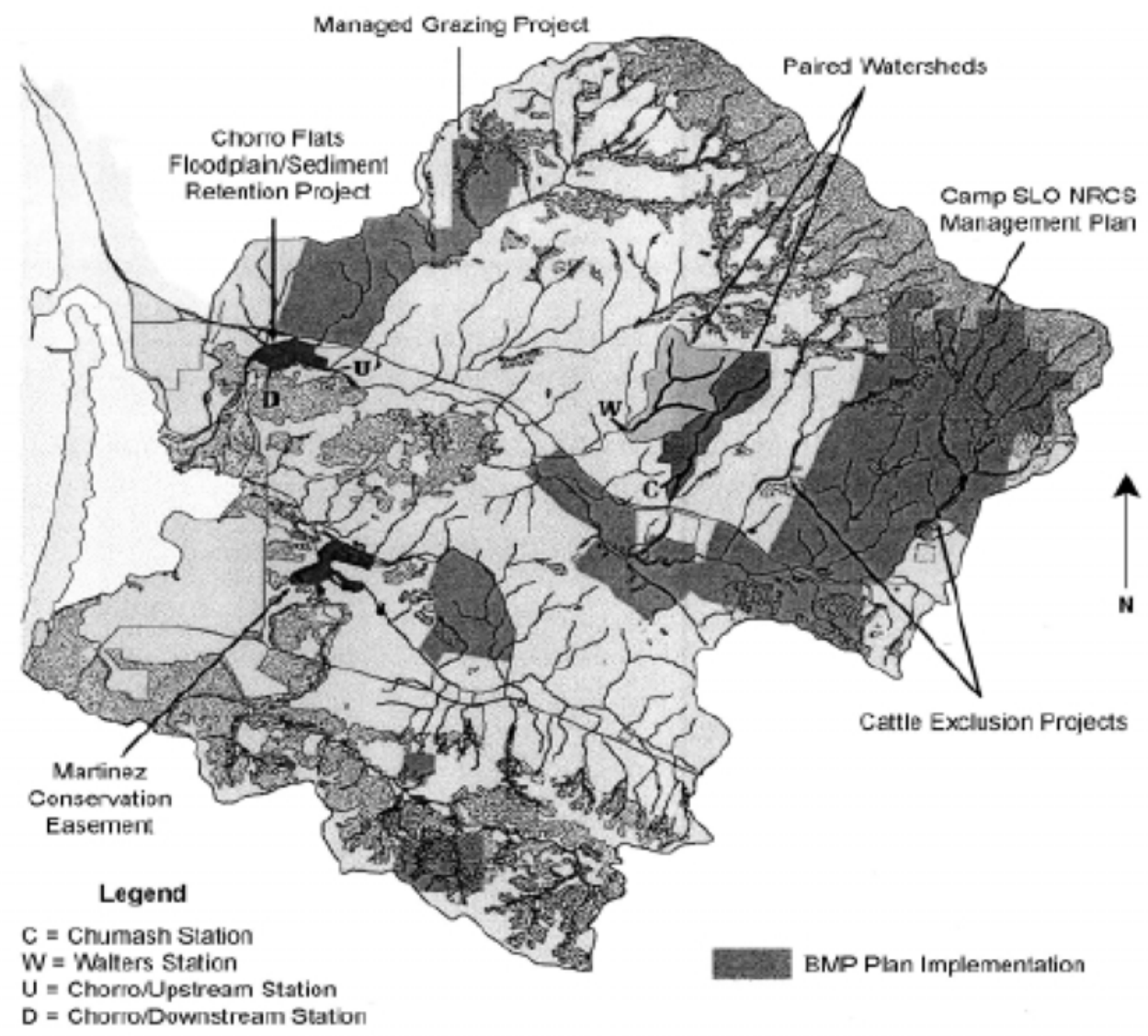

Figure 2: Morro Bay Watershed Map of Major BMPs. (Source: CCRWQCB, 2003)

Walters Creek had no BMPs installed along its reach and was used as a control watershed, while Chumash Creek had various BMPs installed, including grazing management, stream bank stabilization, cattle exclusion fencing projects and planting native riparian trees along stream banks. Observation was conducted over a 10 year study period to determine the effectiveness of BMPs and to calibrate and validate sediment yield. Sediment yield, streamflow, nitrate concentrations, and other water quality parameters were collected during the rainy season for both creeks. This data was reviewed and analyzed to determine the effectiveness of the BMPs installed on Chumash Creek, which was accomplished by evaluating the difference in sediment yield between the pre and post BMP implementation. Walters Creek data was used to normalize the data and remove any fluctuations in sediment yield due to events other than BMP installation.

The Central Coast Regional Water Quality Control Board (CCRWQCB), which is tasked with regulating new and existing sediment discharges in the watershed, conducted a study on the "Morro Bay Total Maximum Daily Load (TMDL) for Sediment (including Chorro Creek, Los Osos Creek and the Morro Bay Estuary).” In the study, the CCRWQCB evaluated many of the contributing factors of sediment to Morro Bay, including flushing action, stream sediment transport, background erosion in the bay, and other contributing factors. The study attributes most of the sedimentation of the bay to "creek-born" sediment transport. The study used data collected by Tetra Tech as part of the paired watershed study and Chorro and Los Osos Creek Monitoring Programs. It was identified that Chorro Creek averages 19,200 tons/year of sediment transport to the bay. 
The study evaluated the various beneficial water users in the basin. The report outlined the various types of users and describes the impacts that sedimentation has had on the users. The study is used to determine the impacts of sedimentation and give a baseline for sedimentation in the region. The report sets future TMDL targets with the primary goal of reducing sediment loading in the basin to reduce the impacts on users in the basin. The TMDL report outlines impacts and discharge types to support regulation findings and permit conditions on potential dischargers.

Over time, all estuaries eventually fill with sediment due to the natural processes of erosion and sedimentation. However, the concern with Morro Bay is that these natural processes have been accelerated due to anthropogenic watershed disturbances. Studies conducted by various authors over the past 25 years have concluded that the rate of sedimentation to Morro Bay has rapidly increased. These studies have provided either estimates of sediment loadings to the Bay from the creeks emptying into the Bay, or estimates of sediment accumulations within the Bay. (CCRWQCB 2003)

Several BMPs were implemented in the Morro Bay Watershed to help reduce sediment transport. The Morro Bay National Estuary Program (MBNEP), conducts routine monitoring of sediment and submits an annual Sediment Monitoring Report for the Morro Bay Watershed, to the CCRWQCB. The MBNEP has groups of volunteers that collect the data throughout the year. The annual report summarizes the years monitoring, assess the state of the watershed, and evaluates effectiveness of installed BMPs.

This paper consolidates the information from the various BMPs that were implemented in the watershed into a global sediment model approach. The BMP evaluation can benefit greatly from the increasing amount of available Geographical Information System (GIS) data. The two goals of this evaluation are to organize and document the various sources of data and analysis that have been performed to date in the Chorro Creek Subwatershed and to present a global evaluation of the effectiveness of the BMPs that have been implemented in this watershed using Soil and Water Assessment Tool 2005 (SWAT), in order to simulate the pre and post BMP implementation characteristics evaluated in the Chorro Creek Subwatershed. Combining the data and efforts of past BMP evaluations, land use, soil type, rainfall, and streamflow data, past statistical evaluations, and model sensitivity analysis helped build and calibrate a robust SWAT model. This model can be used to track BMP evaluation efforts, as well as other watershed management tasks. Through the evaluation of BMPs in the Morro Bay Watershed, efforts can be made to implement the more successful BMPs in the watershed or in other similar watersheds.

\section{The Watershed Simulation Model}

Soil and Water Assessment Tool (SWAT), developed by the USDA's Blacklands Research Center, was used in this study. SWAT is a continuous-time, spatially distributed simulator, developed to assist Water Resource Managers in predicting impacts of land management practices regarding water, sediment and agricultural chemical yields. The model is well suited for large, complex watersheds with varying soils, land use, and management conditions over long periods of time (Nietsch, et al., 2001; Arnold et al., 1998; ASCE, 1999). SWAT uses 
watershed specific information like weather, soil, topography, vegetation, and land use practices to simulate watershed processes such as surface runoff, subsurface flow, streamflow, sediment transport, sediment yield, and nutrient loading, among others. The model is commonly used on a daily time scale. The model spatially divides the watershed into smaller subwatersheds or subbasins based on topography. These subbasins represent small units of the overall watershed that can be used to approximate the behavior of the overall watershed. The subwatersheds are divided further by the model into hydrologic response units (HRUs), which are assigned homogeneous soil type, land use, weather, and slope. This categorization allows the model to create homogeneous units that can be modeled to predict how the heterogeneous properties of the watershed will respond to changes in input parameters, such as rainfall, land use changes, and topography.

As a distributed model, a major concern that may arise with the practicality of SWAT may be its numerous and varied data requirements. For the U.S., the required data is commonly available in high enough resolution from government agencies that a model can be created relatively quickly. For watersheds that lack weather stations, the model has the capability to generate synthetic monthly weather data using a stochastic weather simulator. The ability of SWAT to integrate with the ongoing expansion of ArcGIS data helps alleviate difficulties locating, formatting, and importing data. All these comprehensive features make SWAT an ideal choice for use in integrative watershed management systems.

\section{Watershed Data}

The Chorro Creek Subwatershed was mapped using a high resolution digital elevation map (DEM) to determine the high points that border the watershed. Once the boundaries of the watershed were determined, soil type, land use, precipitation, evapotranspiration, temperature, and other weather data for the watershed were collected from various sources. The data collected was integrated into the SWAT model.

Elevation data was collected for the watershed from the United States Geological Survey (USGS). A DEM of the basin was obtained with a $10 \mathrm{~m}$ by $10 \mathrm{~m}$ resolution. This data was used to help generate the boundaries of the watershed, stream location, and slope parameters in the watershed (Figure 3). Soil type information was obtained from the National Recourses Conservation Service. This data was cross checked with USGS soil data. Soil type is used by SWAT to develop HRU parameters, such as curve number. The county's land use data was used to compile land use types for the model. SWAT uses land use to calculate HRU parameters and determine hydrologic responses to rainfall. Land use was altered to simulate installation of BMPs in the watershed. Detailed continuous rainfall data was not available in the watershed area. Rainfall in the urban community of Morro Bay was used to estimate historic rainfall information for the basin. The location of this data is a possible source of uncertainty in the calibration of the model. Streamflow data was collected for the Canet Road stream gage located in the basin (see Figure 2). This gage is monitored by the County of San Luis Obispo Department of Public Works. The data at the Canet streamgage location was converted from stage readings to streamflow using a rating curve obtained from streamflow monitoring conducted by the MBNEP and the City of Morro Bay. Flow data was also obtained for Walters and Chumash creeks from the Paired Watershed Study data. Sediment data was compiled from 
the existing data collection efforts in the basin. The MBNEP and NRCS have conducted numerous sediment studies. This data is not currently monitored continuously and is another potential source of uncertainty in the calibration step of the SWAT model.

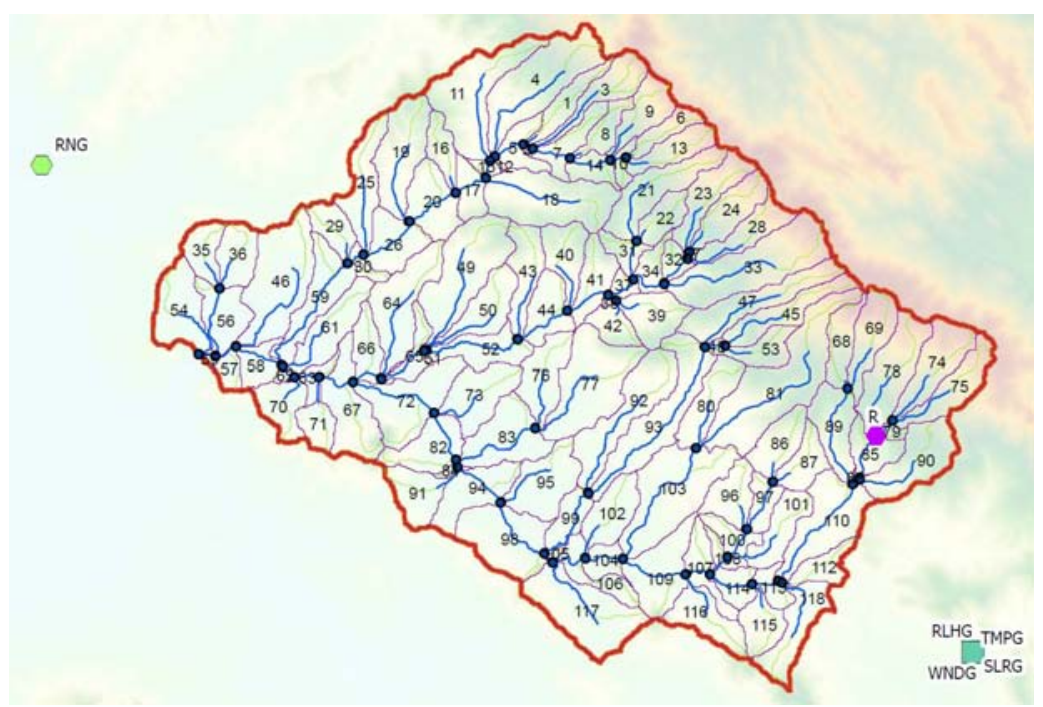

Figure 3: ArcSWAT Model Map

\section{Sensitivity Analysis and Calibration}

A sensitivity analysis was conducted to determine which of the unknown variables have the largest effect on the sediment yield and streamflow in the model. The results from the sensitivity analysis indicated which variables were the most influential variables. The most influential variables were selected as variables in the calibration stage of the modeling effort. Sensitivity analysis was performed using a sensitivity analysis method known as One-at-a-Time (OAT) and streamflow and sediment yield were calibrated using Shuffled Complex Evolution-University of Arizona (SCE-UA). The results from the sensitivity analysis are shown below in Table 1. The five highest ranked parameters have the largest effect on sediment yield and streamflow.

Once the sensitive parameters were identified, calibration was performed. Calibration refers to the process of identifying the "best" set of model parameters to match the simulated outputs and observed data. Calibration is typically accomplished by changing input parameters and determining what input parameters yield simulated outputs that match the observed data from the field. SWAT uses SCE-UA to adjust input parameters and compare simulated and observed outputs. The Chorro Creek Watershed model was calibrated using SCE-UA to alter the five highest ranked sensitivity result parameters using observed streamflow data at Canet. Comparison of the calibrated and the observed flow is given in Figure 4. After running calibration, the model is rerun with the optimized parameters from calibration to produce the most accurate model output. The optimal SWAT parameters identified during calibration were applied to all of the subwatersheds in the Chorro Creek Watershed to estimate sediment yield that would have been produced from the entire watershed if no BMPs were installed. 
Table 1: Sensitivity Analysis Results

\begin{tabular}{|l|l|l|}
\hline Parameter & Rank & Mean \\
\hline Cn2 & 1 & 0.696 \\
\hline Alpha_Bf & 2 & 0.323 \\
\hline Esco & 3 & 0.297 \\
\hline Sol_Z & 4 & 0.244 \\
\hline Sol_Awc & 5 & 0.0972 \\
\hline Gwqmn & 6 & 0.0639 \\
\hline Blai & 7 & 0.0613 \\
\hline Revapmn & 8 & 0.0330 \\
\hline Canmx & 9 & 0.0317 \\
\hline Sol_K & 10 & 0.0296 \\
\hline
\end{tabular}

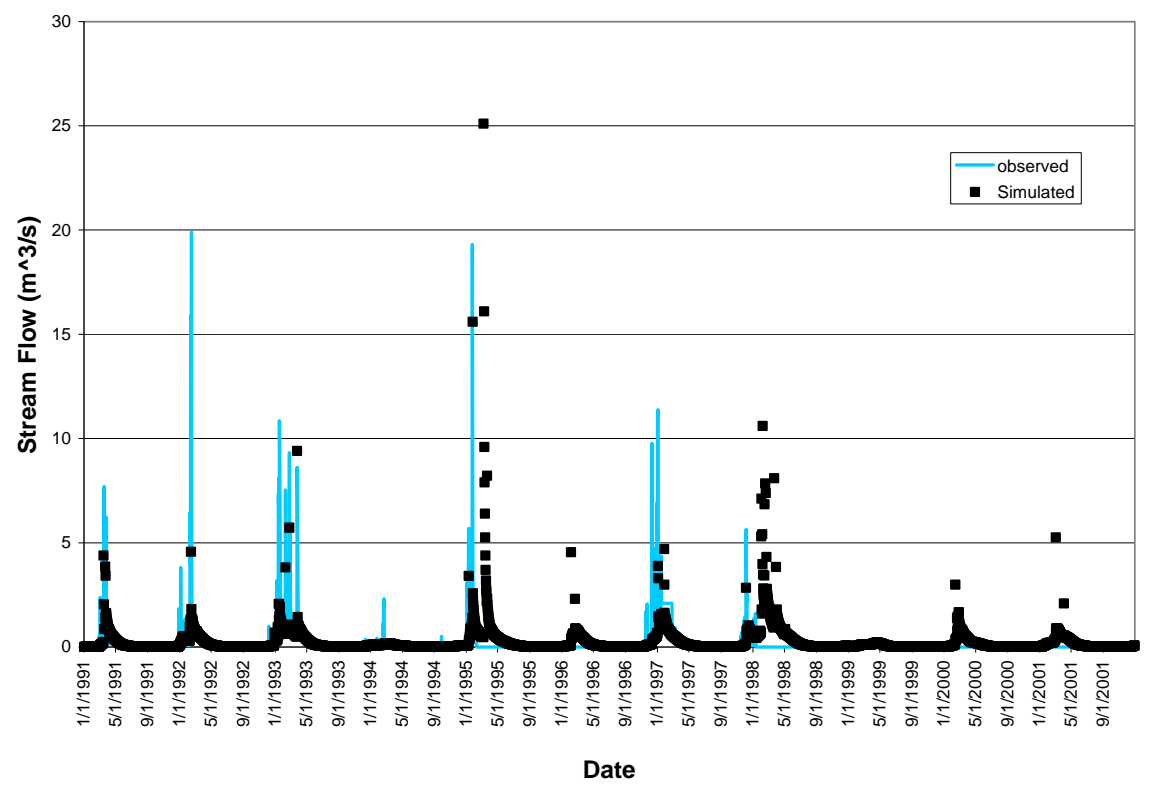

Figure 4: Comparison of Simulated and Observed Streamflow for Canet Road

\section{Results and Discussion}

To estimate sediment yield from the watershed for the post-BMP implementation scenario, SWAT parameters that were believed to be affected by the BMPs installed in the specific subwatershed were modified using guidance by literature (Arbi et al. (2007), Bracmort et al. (2006)). As the major BMPs were installed before 1998, the post-BMP scenario simulation was done for the 1998-2008 period. Annual average sediment yield values obtained for the with BMP and the without BMP scenarios were compared to evaluate effectiveness of the BMPs. Sediment transport behavior of the stream channels in the lower part of the watershed are not calibrated in this study due to lack of data at lower reaches of the basin. Only streamflow calibration was performed for the lower portion of the watershed. In spite of this accuracy issue with regards to the sediment that gets to the mouth of the watershed where the Chorro Flats 
project is located, effectiveness of the Chorro Flats project was also evaluated based on sediment yield estimates obtained at the upstream and downstream ends of the project. To model the Chorro Flats project, the stream channel that passes through the project was modified to make it shallower and milder to allow overtopping of the main channel into the adjacent field where sediment should deposit. Slope of the subwatershed was also reduced to enable deposition of sediment in the flat. For cattle exclusion projects and channel stabilization projects, model parameters that simulate erodibility of the channel were modified along with land use.

For the Chorro Creek Watershed, average annual sediment yield obtained was 4.81 tons/ha and 5.20 tons/ha for the with and without BMP scenarios, respectively. This shows approximately an 8 percent reduction in sediment yield from the entire Chorro Creek watershed due to the BMPs implemented in Chumash Creek watershed, the cattle exclusion project in Dairy Creek watershed, the cattle exclusion project downstream of Chorro reservoir and the grazing management project in the San Bernardo Creek Watershed. Improvement in sediment reduction achieved at the local subwatersheds where the BMPs are installed is as high as 50 percent. Most of these BMP projects would also help reduce erodibility of the stream banks and could decrease sediment that leaves the subwatershed. This role was not factored into the 8 percent figure indicated here.

Although additional information is needed to conclusively determine the effectiveness of BMP implantation, SWAT can be used to predict BMPs and locations that will be most effective in the watershed. Once the analysis is complete, BMPs can be ranked as a suggestion of BMPs that should be implemented in the basin to reduce sediment transport through Chorro Creek to Morro Bay. While the accurate quantities of sediment transport prevention can not be determined with the data that is currently available, the model can be used to screen BMPs options and provide guidance on relative effectiveness of the various BMPs.

Through the development of this paper, it was discovered that additional data in the Chorro Creek Watershed is needed to develop a broader dataset before detailed conclusions can be drawn from any modeling effort. The most critical data to collect to evaluate watershed management strategies is sediment data and rainfall data in the watershed during high flow events. The various organizations and agencies focused on the sediment issues in the basin should collectively focus resources on gathering quality sediment and rainfall data in the watershed to both predict future BMP implementation impacts and monitor the impacts of existing BMPs. 


\section{References}

Arabi, M., Frankenberger, J.R., Engel, B.A., and Arnold, J.G. (2007). "Representation of agricultural conservation practices with SWAT”, Hydrol. Process., DOI: 10.1002/hyp.6890

Arnold, J.G., Williams, J.R., Srinivasan, R., and King, K.W. (1999). SWAT: Soil and Water Assessment Tool. U.S. Department of Agriculture, Agricultural Research Service, Temple, TX.

Bracmort, K.S., Arabi, M., Frankenberger, J.R., Engel, B.A., and and Arnold, J.G. (2006). "Modeling Long-Term Water Quality Impact of Structural BMPs." Transactions of the ASABE, 49(2): 367-374.

CCRWQCB (2002). "Morro Bay Total Maximum Daily Load for Sediment (including Chorro Creek, Los Osos Creek, and the Morro Bay Estuary).” State of California Central Coast Regional Water Quality Control Board, San Luis Obispo, CA.

CSLRCD (2002). "Chorro Flats Enhancement Project, Final Report to the California State Costal Conservancy.”

Kitajima, Ann (2010). Morro Bay National Estuary Program. "Morro Bay National Estuary Program's Implementation Effectiveness Program for the Morro Bay Watershed, Data Summary Report 2010.” Morro Bay, CA

Morro Bay National Estuary Program (2010). “Morro Bay National Estuary Program’s Implementation Effectiveness Program for the Morro Bay Watershed, Suspended Sediment Monitoring Report 2009-2010.” Morro Bay, CA.

Morro Bay National Estuary Program. (2009). “Morro Bay National Estuary Program’s Implemenation Effefiveness Program for the Morro Bay Watershed, Data Summary Report 2008.” Morro Bay, CA.

Neitsch, S.L., Arnold, J.G., Kiniry, J.R., and Williams, J.R. (2005). Soil and Water Assessment Tool Theoretical Documentation. Version 2005. Grassland, Soil and Water Research Service, Temple, TX.

Tetra Tech (1998). Morro Bay National Estuary Program: Sediment Loading Study. Lafayette, CA.

Tolson and Shoemaker (2004). Watershed Modeling of the Cannonsville Basin using SWAT2000. Cornell University. 